\title{
Analytical Electron Microscopy of W-Core $\beta$-SiC Fibers for Use in an SiC-Based Composite Material for Fusion Applications
}

\author{
Tea Toplišek, Medeja Gec, Aljaž Iveković, Saša Novak, Spomenka Kobe, and Goran Dražić* \\ Jozef Stefan Institute, Department for Nanostructured Materials, Jamova cesta 39, SI-1000 Ljubljana, Slovenia
}

\begin{abstract}
In this work, the interactions between tungsten (W) and silicon carbide ( $\mathrm{SiC}$ ) in Sigma ${ }^{\mathrm{TM}} \mathrm{SiC}$ fibers at high temperatures were characterized using scanning and transmission electron microscopy. These fibers could have the potential for use in fusion-related applications owing to their high thermal conductivity compared with pure SiC-based fibers. The as-received fibers were composed of a $100-\mu \mathrm{m}$-thick shell of radially textured $\beta$-SiC grains and a $15-\mu \mathrm{m}$-thick tungsten core, composed of a few hundreds of nm-sized elongated tungsten grains. The interfaces between the tungsten and the $\mathrm{SiC}$ and the $\mathrm{SiC}$ and the outer coatings were sharp and smooth. After heat treatment at $1,600^{\circ} \mathrm{C}$ for $3 \mathrm{~h}$ in $\mathrm{Ar}$, the tungsten core reacted with $\mathrm{SiC}$ to form a rough interface surface. Inside the core, $\mathrm{W}_{5} \mathrm{Si}_{3}, \mathrm{~W}_{3} \mathrm{Si}$, and $\mathrm{W}_{2} \mathrm{C}$ phases were detected using energy-dispersive $\mathrm{X}$-ray spectroscopy and electron-diffraction techniques. The mechanical properties of the fibers deteriorate after the heat treatment.
\end{abstract}

Key words: SEM, TEM, silicon carbide, fibers, fusion

\section{INTRODUCTION}

Silicon carbide (SiC)-based fiber/matrix composite materials are, owing to their low activation in a neutron flux, an operating temperature $>1,000^{\circ} \mathrm{C}$, and radiation defects resistance, practically the only nonmagnetic materials that could be used in structural applications in the next generation of fusion reactors. Besides the mentioned properties, the composite should have a high wear resistance under the conditions of service, a resistance to structural or lattice damage owing to the impinging high-energy neutrons, a high thermal conductivity, and a gas impermeability (Hasegawa et al., 2000; Naslain, 2004; Andreani et al., 2006; Lässer et al., 2007; Novak et al., 2010). The SiC should be in the cubic $(\beta)$ form, which is less prone to irradiation damage and with a very small amount of porosity.

According to the present state of the art, a composite material prepared by chemical vapor infiltration (CVI) and polymer infiltration and pyrolysis does not completely meet the required properties. Although the CVI method enables the production of pure $\mathrm{SiC}$ with very low neutron activation, both methods are very slow and costly and/or result in an incomplete filling of the gaps between the fibers in the tows. The porosity at the micro and macro levels, the gas permeability, and the thermal conductivity are still not in the required range (Chawla, 1987; Hasegawa et al., 2000). The preparation temperature of the matrix material is expected to be around $1,600^{\circ} \mathrm{C}$, with an operating temperature around $1,000^{\circ} \mathrm{C}$.

Insufficient thermal conductivity is one of the main drawbacks to $\mathrm{SiC} / \mathrm{SiC}$ composites proposed for use in the

(C) MICROSCOPY SOCIETY OF AMERICA 2013

${ }^{*}$ Corresponding author. E-mail: goran.drazic@ijs.si structural parts of a fusion reactor beyond ITER. One possible solution to increasing the thermal conductivity is the incorporation of tungsten filaments in the composite material, with its intrinsic room temperature thermal conductivity being $170 \mathrm{~W} / \mathrm{mK}$. With the proper amount and geometry of $\mathrm{W}$ filaments through the thickness in a SiCbased matrix, the requested thermal conductivity of 30 $\mathrm{W} / \mathrm{mK}$ should be achieved. As an alternative to pure $\mathrm{W}$ filaments, SiC-coated W or W-core SiC fibers could be used.

The main objective of the work is the potential interactions between $\mathrm{W}$ and $\mathrm{SiC}$ in $\mathrm{W}$-core SiC fibers at high temperatures. According to the literature data (Chawla, 1987; Harris, 2002; Wawner, 2000), the reaction products may have a detrimental or, if controlled, beneficial effect on the mechanical properties of the material. The W/SiC interfaces were investigated with scanning and transmission electron microscopy (SEM and TEM) and microanalysis. The preparation of the electron-transparent sections of the ceramic fibers is a challenging task that often limits the use of TEM studies for such fibers. Various TEM sample preparation methods were tested; the most efficient method combines a technique for preparing densely packed fiber/epoxy specimens and mechanical polishing to a thickness of $<5 \mu \mathrm{m}$, thus minimizing the time of the ion milling. Alternatively, the wedge-polishing method without any ion milling was also used.

\section{Materials and Methods}

As model materials, different grades of Sigma fibers from TISICS Ltd, UK were used: SM 1040, SM 1240, SM 3156, and Hot Fiber. All the fibers consist of a $15-\mu \mathrm{m}$ W-core with deposited $\mathrm{SiC}$ with various grades of purity and stoichiometry on the top. In some cases, different outer coat- 
ings were added to the SiC. The SM 1040 fiber has a total diameter of $\sim 95 \mu \mathrm{m}$ with no outer coating, and the SM 1240 fiber has a diameter of $\sim 105 \mu \mathrm{m}$ with $\sim 3-4 \mu \mathrm{m}$ carbon and $0.8-1.2 \mu \mathrm{m}$ titanium boride outer coatings. In both cases, the $\mathrm{SiC}$ is nonstoichiometric with some free silicon and silicon-rich phases. The SM 3156 fiber is $\sim 140 \mu \mathrm{m}$ in diameter, with $\sim 3-4 \mu \mathrm{m}$ carbon outer coating. The $\mathrm{SiC}$ is almost stoichiometric. Hot Fiber is a titaniumcarbide-coated $\mathrm{W}$-core with an $\mathrm{SiC}$ layer. All the fibers were thermally treated at $1,600^{\circ} \mathrm{C}$ for $3 \mathrm{~h}$ in pure Ar. The selected conditions are comparable to the conditions for the production of SiC-based composite material.

The microstructure of the fibers, the interactions between the $\mathrm{W}$-core and the $\mathrm{SiC}$, and the interactions between the $\mathrm{SiC}$ and outer coatings were investigated with scanning (JEOL FEG-SEM 7600F) and transmission (JEOL $2010 \mathrm{~F}$ FEGSTEM) electron microscopy and microanalysis. Highresolution TEM, Z-contrast imaging (STEM/HAADF), and different techniques of electron diffraction were used for the phase identification and energy-dispersive X-ray spectroscopy (EDXS) for determining the chemical composition of the individual phases.

\section{TEM Specimen Preparation}

One batch of TEM samples was prepared from a glued bundle of fibers by mechanical polishing on a diamondlapping film in the longitudinal section down to a thickness of $\sim 10 \mu \mathrm{m}$. The thinned samples were milled in an ion miller (Bal-Tec RES 010, Balzers) at $4 \mathrm{keV}$ with an incidence angle of $10^{\circ}$ until a perforation was observed.

To get enough thin area at the $\mathrm{W} / \mathrm{SiC}$ interface, the specimens were also prepared using a wedge-shaped polishing cross-section method using an automatic Allied MultiPrep System. The fibers, embedded with epoxy resin and placed in preformed channels between two monocrystalline silicon plates (Fig. 1a), were polished on diamond-lapping films at a very small wedge angle of $1.5^{\circ}$ until interference fringes became visible under the optical microscope. The final polishing step involved a $0.5-\mu \mathrm{m}$ diamond-lapping film and $0.05-\mu \mathrm{m}$ colloidal silica until the electron transparency was observed (Fig. 1b). The specimens were removed from the glass support and mounted on a $\mathrm{Cu}$ grid for the TEM observation (Voyles et al., 2003; Eberg et al., 2008).

\section{Results AND Discussion}

Figure 2 shows the optical and FEG-SEM micrographs of the as-received SM 1240 and SM 3156 fibers' microstructure at room temperature. It consists of the $\mathrm{W}$-core, $\mathrm{SiC}$, and various outer coatings, such as carbon and titanium boride (SM 1240) and carbon coating (SM 3156). The W-core is composed of a few hundreds of nm-sized W-grains (Fig. 3a), elongated in the longitudinal direction. The $\mathrm{SiC}$ phase consisted of around $1 \mu \mathrm{m}$, radially textured, $\beta$-SiC crystals (Fig. 3b), confirmed with electron diffraction. The interfaces between the $\mathrm{SiC}$ and the other coatings are sharp and smooth. In the optical microscopy images, some gradients
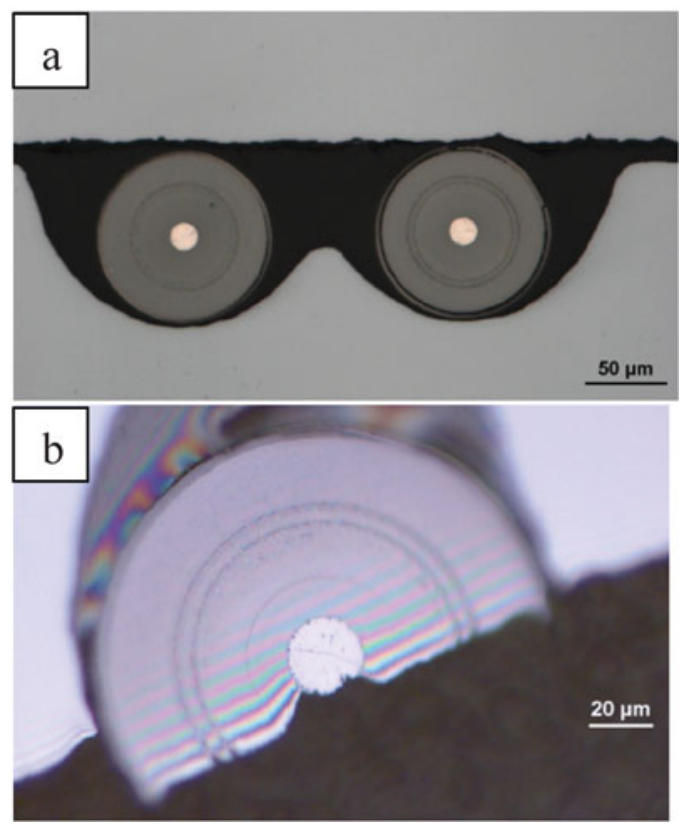

Figure 1. Optical micrographs of tripod-polished specimen using a wedge-shape method for the W/SiC interface: (a) before polishing and (b) after the procedure, the interference fringes at the edge of the specimen are clearly visible.

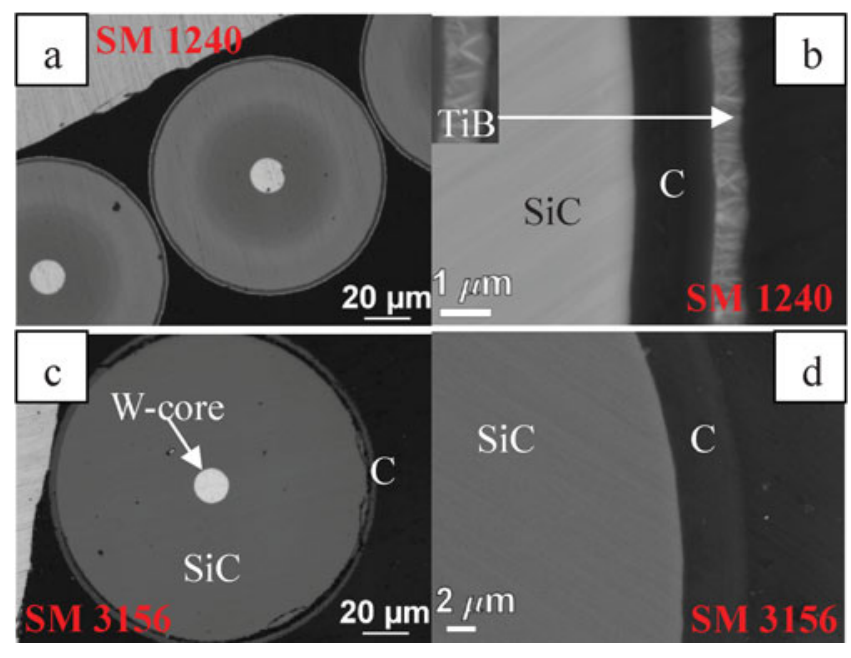

Figure 2. Optical and FEG-SEM micrographs of the SM 1240 $(\mathbf{a}, \mathbf{b})$ and SM 3156 (c, d) fibers' microstructure at room temperature. It consists of the tungsten core, $\mathrm{SiC}$, and different outer coatings. The SM 1240 fiber has carbon and titanium boride coatings and the SM 3156 fiber has a carbon coating.

of color (brightness) inside the $\mathrm{SiC}$ phase were observed in all the samples except in SM 3156 (Fig. 2a). These gradients most probably originated from the nonstoichiometry of the $\mathrm{SiC}$ and the different grain size across the diameter. Minor changes in the conditions during the preparation of the fibers can lead to a significantly different microstructure within SiC (Cheng et al., 1999). The carbon layer is amorphous in all samples; in SM 3156, an up to $0.5-\mu \mathrm{m}$-thick amorphous SiC layer was found to be present. Outer layers (carbon, titanium boride, or amorphous $\mathrm{SiC}$ ) were added 


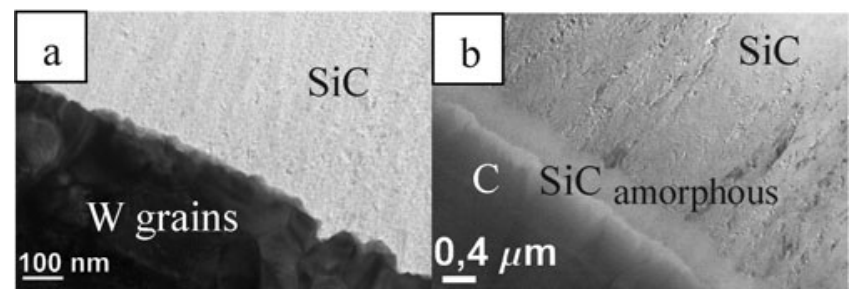

Figure 3. Transmission electron microscope (TEM) micrograph (bright-field image) of the W/SiC interface (a) and TEM micrograph of the $\mathrm{C} / \mathrm{SiC}$ interface (b) in sample SM 3156 at room temperature. The $\mathrm{SiC}$ crystal grains are radially textured.

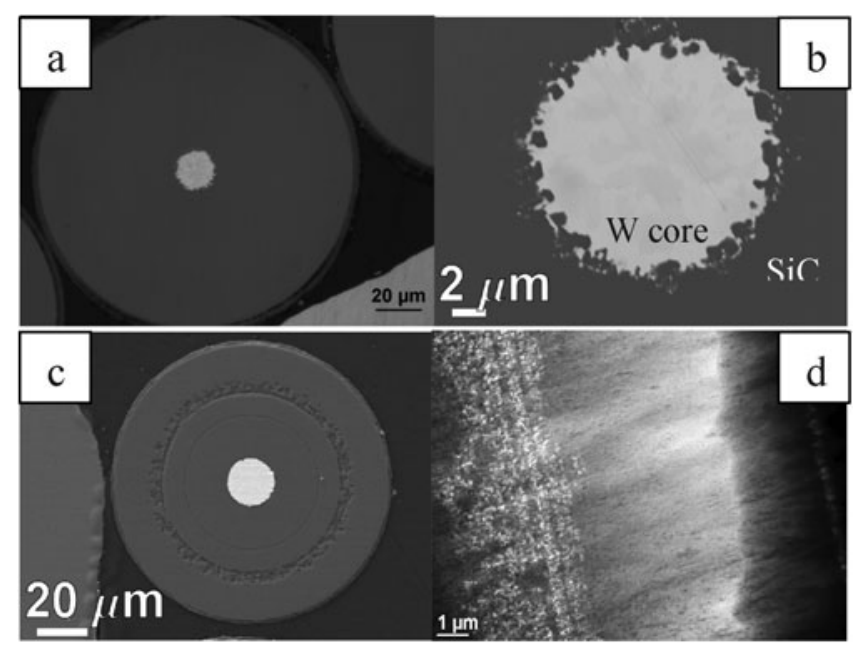

Figure 4. FEG-SEM micrographs of SM 3156 fiber (a,b) and Hot Fiber (c). Transmission electron microscope micrograph of W/SiC interface in Hot Fiber (d) after heating at $1,600^{\circ} \mathrm{C}$ for $3 \mathrm{~h}$ in pure Ar. W-core reacted with $\mathrm{SiC}$ forming a rough $\mathrm{W} / \mathrm{SiC}$ interface. The ring defects in the fiber are rich in oxygen and calcium.

during the fabrication of the fibers to prevent the reaction between the fibers and the matrix material and to enhance the mechanical properties by enabling crack deflection at the matrix/fiber interface.

After heating the samples at $1,600^{\circ} \mathrm{C}$ for $3 \mathrm{~h}$ in pure Ar, the $\mathrm{W}$-core reacted with $\mathrm{SiC}$ forming a rough $\mathrm{W} / \mathrm{SiC}$ interface, which is seen in Figures $4 \mathrm{a}$ and $4 \mathrm{~b}$. In all the samples except SM 3156 (the only one with stoichiometric SiC), circular defects with a large quantity of pores were found. Traces of oxygen and calcium were detected at the circular defects using SEM/EDXS (Figs. 4c, 4d). These defects were most probably formed during heat treatment owing to the partial densification (sintering) of the originally nonuniformly dense $\mathrm{SiC}$ material.

The changes inside the $\mathrm{W}$-core and the possible reactions between the $\mathrm{SiC}$ and $\mathrm{W}$ after heating were explained with a ternary phase diagram in the $\mathrm{W}-\mathrm{Si}-\mathrm{C}$ system at $1,800^{\circ} \mathrm{C}$, which is presented in Figure 5 (Brukl, 1965). The possible compounds at that temperature are $\mathrm{W}, \mathrm{W}_{2} \mathrm{C}, \mathrm{WC}$, $\mathrm{W}_{5} \mathrm{Si}_{3}, \mathrm{WSi}_{2}, \mathrm{SiC}$, and $\mathrm{C}$. Three main phases, presented in Figure 6, were found inside the W-core using EDXS and electron diffraction: $\mathrm{W}_{5} \mathrm{Si}_{3}, \mathrm{~W}_{3} \mathrm{Si}$, and $\mathrm{W}_{2} \mathrm{C}$. The presence of these phases was determined with EDXS analyses and elec-

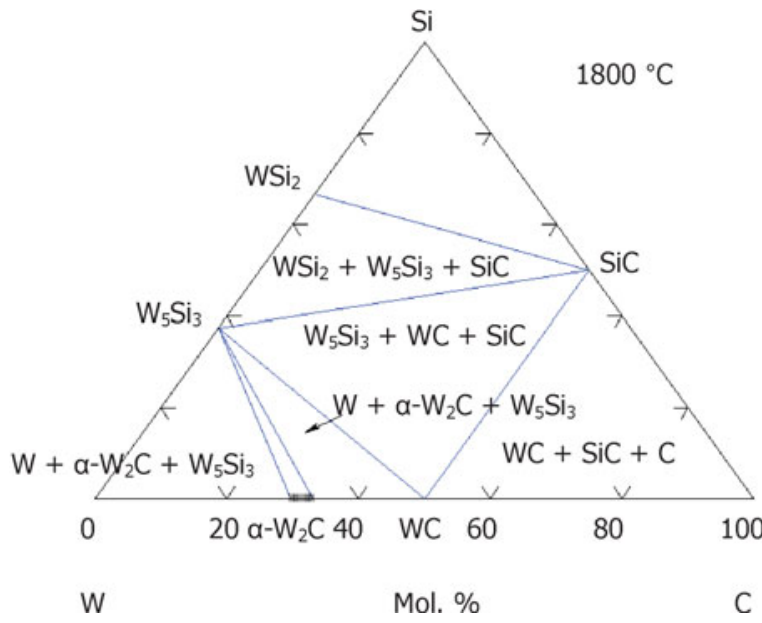

Figure 5. Possible phases in the ternary phase diagram in the $\mathrm{W}-\mathrm{Si}-\mathrm{C}$ system at $1,800^{\circ} \mathrm{C}$.

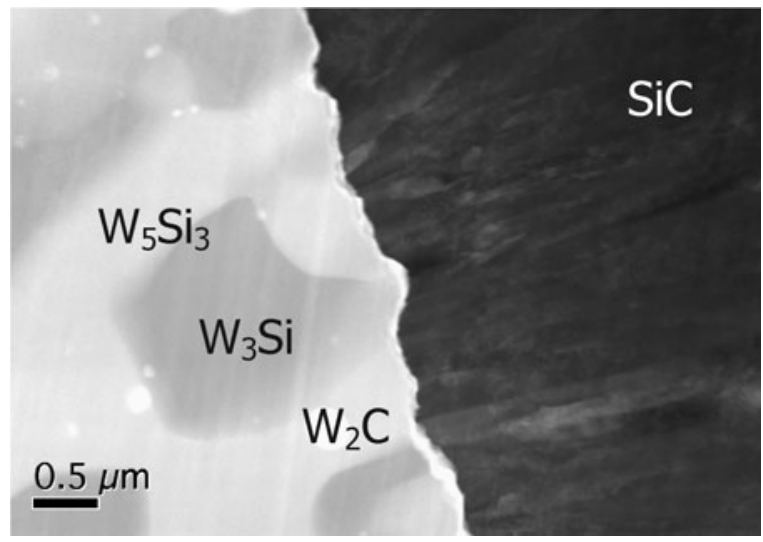

Figure 6. STEM/HAADF (Z-contrast) micrograph of W/SiC interface in Hot Fiber after thermal treatment at $1,600^{\circ} \mathrm{C}$ for $3 \mathrm{~h}$ in pure Ar. Inside the $\mathrm{W}$-core, $\mathrm{W}_{5} \mathrm{Si}_{3}, \mathrm{~W}_{3} \mathrm{Si}$, and $\mathrm{W}_{2} \mathrm{C}$ phases were detected.

tron diffraction. The differences in the contrasts of the various phases in Figure 6 are a consequence of the imaging method, sample thickness, and diffraction contrast. The intensity of the signal in the Z-contrast imaging should be approximately proportional to $Z^{2}$, but still some classical diffraction contrast could also be present. Owing to the differences in the mechanical properties, various phases were thinned down to different thicknesses, which would also have a strong influence on the intensity. This could explain the unusual contrasts in Figure 6, where the phases with a higher $Z\left(\mathrm{~W}_{3} \mathrm{Si}\right)$ are darker than the phases with a lower $Z\left(\mathrm{~W}_{5} \mathrm{Si}_{3}\right)$.

After the heat treatment, the fibers become extremely brittle and very difficult to handle.

\section{CONCLUSIONS}

The use of Sigma ${ }^{\text {TM }}$ fibers composed of a W-core and an $\mathrm{SiC}$ shell, as a reinforcement in a ceramic composite material based on $\mathrm{SiC}$, is an attractive option to increase the thermal conductivity of the structural material with a poten- 
tial to be used in a future fusion reactor. The SEM and TEM microstructural investigations of the as-received and thermally treated $\left(1,600^{\circ} \mathrm{C}, 3 \mathrm{~h}\right)$ fibers were performed. On summarizing the results, we found the following.

Fibers are composed of a $100-\mu \mathrm{m}$-thick shell of radially textured $\beta$-SiC crystals. The $15-\mu \mathrm{m}$-thick $\mathrm{W}$-core is composed of a few hundreds of nm-sized elongated W-grains. The interfaces between the $\mathrm{W}$ and the $\mathrm{SiC}$ and the $\mathrm{SiC}$ and the outer coatings were sharp and smooth.

After heat treatment at $1,600^{\circ} \mathrm{C}$ for $3 \mathrm{~h}$ in $\mathrm{Ar}$, the $\mathrm{W}$-core reacted with the $\mathrm{SiC}$ forming a rough interface surface. Inside the core, the $\mathrm{W}_{5} \mathrm{Si}_{3}, \mathrm{~W}_{3} \mathrm{Si}$, and $\mathrm{W}_{2} \mathrm{C}$ phases were found. Circular defects with a large amount of pores were present inside the $\mathrm{SiC}$ layer in samples with nonstoichiometric $\mathrm{SiC}$ where small concentrations of the elements $\mathrm{Ca}$, $\mathrm{Ti}$, and $\mathrm{O}$ were found. The reaction of the $\mathrm{W}$-core with the $\mathrm{SiC}$ layer worsens the mechanical properties, and Sigma fibers of the investigated grades could not be directly used for SiC-based composite material preparation. Introducing some buffer layer between the $\mathrm{W}$ and the $\mathrm{SiC}$, which would prevent the diffusion across the interface, would probably solve the described problems.

\section{ACKNOWLEDGMENTS}

The authors thank TISICS Ltd. for providing the Sigma ${ }^{\mathrm{TM}}$ $\mathrm{SiC}$ fibers. This work was performed under the contract P2-0084 and was financially supported by the Slovenian Research Agency and the European Commission within the Contract of Association Euratom FU06-CT-2004-00083. The work forms part of the doctorate thesis of Tea Toplišek.

\section{REFERENCES}

Andreani, R., Diegele, E., Gulden, W., Lässer, R., Maisonnier, D., Murdoch, D., Pick, M. \& Poitevin, Y. (2006). Overview of the European Union fusion nuclear technologies development and essential elements on the way to DEMO. Fusion Eng Des $\mathbf{8 1}, 25-32$.
BRukL, C.E. (1965). Part II. Ternary systems. Volume VII. The $\mathrm{Ti}-\mathrm{Si}-\mathrm{C}, \mathrm{Nb}-\mathrm{Si}-\mathrm{C}$, and $\mathrm{W}-\mathrm{Si}-\mathrm{C}$ systems, ternary phase equilibria in transition metal-boron-carbon-silicon systems, Report No. AFML-TR-65-2, Contract No. USAF 33(615)-1249, Air Force Materials Laboratory; Wright-Patterson Air Force Base, Ohio, pp. 1-57.

Chawla, K.K. (1987). Composite Materials: Science and Engineering. New York: Springer-Verlag.

Cheng, T.T., Jones, I.P., Shatwell, R.A. \& Doorbar, P. (1999). The microstructure of sigma $1140+$ SiC fibers. Mater Sci Eng A260, 139-145.

Eberg, E., Monsen, A.F., Tybell, T., van Helvoort, A.T.J. \& Holmestad, R. (2008). Comparison of TEM specimen preparation of perovskite thin films by tripod polishing and conventional ion milling. J Electron Microsc 57, 175-179.

Harris, B. (2002). In Composite Materials Handbook, MIL-HDBK17-5. vol. 5. Ceramic matrix composites. Department of Defense Handbook.

Hasegawa, A., Kohyama, A., Jones, R.H., Snead, L.L., Riccardi, B. \& Fenici, P. (2000). Critical issues and current status of $\mathrm{SiC} / \mathrm{SiC}$ composites for fusion. J Nucl Mater 283-287, 128-137.

Lässer, R., Baluc, N., Boutard, J.L., Diegele, E., Dudarev, S., Gasparotto, M., Möslang, A., Pippan, R., Riccardi, B. \& Van Der SchaAf, B. (2007). Structural materials for DEMO: The EU development, strategy, testing and modelling. Fusion Eng Des 82, 511-520.

NASlain, R. (2004). Design, preparation and properties of nonoxide CMCs for application in engines and nuclear reactors: An overview. Composites Sci Technol 64, 155-170.

Novak, S., Dražıć, G., König, K. \& Iveković, A. (2010). Preparation of $\mathrm{SiC}_{\mathrm{f}} / \mathrm{SiC}$ composites by the slip infiltration and transient eutectoid (SITE) process. J Nucl Mater 399, 167-174.

Voyles, P.M., Grazul, J.L. \& Muller, D.A. (2003). Imaging individual atoms inside crystals with ADF-STEM. Ultramicroscopy 96, 251-273.

WAWNER, F.E. (2000). Boron and silicon carbide fibers (CVD). In Fiber Reinforcements and General Theory of Composites, Vol. 1 of Comprehensive Composites Materials, Chou, T.-W. (Ed.), pp. 85-105. Oxford, UK: Elsevier Science, Ltd. 